\title{
Realidade Aumentada no Desenvolvimento da Habilidade de Visualização Espacial de Estudantes em Física
}

\author{
Fabrício Herpich $^{1}$, Renan Luigi Martins Guarese ${ }^{2}$, Amaury Teixeira Cassola ${ }^{2}$, \\ Liane Margarida Rockenbach Tarouco ${ }^{1}$ \\ ${ }^{1}$ Programa de Pós-Graduação em Informática na Educação \\ ${ }^{2}$ Instituto de Informática \\ Universidade Federal do Rio Grande do Sul (UFRGS) \\ Porto Alegre - RS - Brasil \\ \{fabricio.herpich, rlmguarese, amaury.cassola\}@inf.ufrgs.br, \\ liane@penta.ufrgs.br
}

\begin{abstract}
Experiential activities in classrooms and their repercussions in the process of building senses (or meanings) are of great value for the cognitive development of students. In this perspective, this paper presents implementation of an augmented reality app in which the objective is to contribute to the process of developing the spatial visualization ability of Physics students through the interaction with multimedia resources and educational objects for the demonstration of invisible occurrences and situations involving natural phenomena.
\end{abstract}

Resumo. As atividades experienciais nas salas de aula e suas repercussões no processo de construção de sentidos (ou significados) são de grande valor para o desenvolvimento cognitivo dos estudantes. Nesta perspectiva, este artigo apresenta a implementação de um aplicativo de realidade aumentada no qual o objetivo é contribuir no processo de desenvolvimento da habilidade de visualização espacial de estudantes de Física, através da interação com recursos multimídia e objetos educacionais para a demonstração de ocorrências invisíveis e situações que envolvem fenômenos naturais.

\section{Introdução}

Ensinar e aprender conteúdos científicos é uma tarefa dificil, como é relatado em inúmeros trabalhos. Os professores nem sempre têm condições de oferecer atividades práticas devido à falta de laboratórios nas escolas e, além disso, vários experimentos não são capazes de expor completamente os comportamentos naturais que estão ocorrendo uma vez que certos fenômenos não são visíveis ao olho humano, como a eletricidade, o magnetismo e o calor, por exemplo. Alguns podem até mesmo acarretar em riscos ambientais ou pessoais (como a radioatividade) e, portanto, não podem ou não devem ser realizados sem as devidas medidas de segurança, o que impede que sejam realizados na maioria das escolas e até mesmo em algumas universidades.

O déficit brasileiro na área das ciências é demonstrado na última avaliação realizada pelo Programme for International Student Assessment (PISA) - Programa Internacional de 
Avaliação de Estudantes - em 2015, na qual aproximadamente 32 mil alunos brasileiros (de 964 escolas) cursando a partir do $7^{\circ}$ ano do Ensino Fundamental participaram da avaliação com foco em ciências. Os resultados demonstraram que o desempenho dos alunos no Brasil está abaixo da média em relação aos demais alunos dos países da Organização para Cooperação e Desenvolvimento Econômico em ciências (401 pontos, comparados à média de 493 pontos dos demais países) (PISA, 2018).

Em relação ao ensino de Física no Brasil, Heck et al. (2016) descrevem que o mesmo tem sido praticado repetidamente por meio da apresentação de conceitos, leis, fórmulas matemáticas e resolução de exercícios que pouco se relacionam com a realidade dos alunos, dificultando o entendimento desses conteúdos. Outra dificuldade em ensinar e aprender física, pode ser explicada pela alta exigência da habilidade imaginativa dos estudantes, em virtude de que os fenômenos físicos muitas vezes são abstratos ou então microscópicos, sendo apenas visualizáveis com o uso de equipamentos de ampliação e, assim, pouco acessíveis aos alunos.

Eventuais dificuldades neste processo que envolvem as operações mentais de abstração podem vir a comprometer o pleno entendimento dos estudantes sobre o assunto que está sendo apresentado em sala de aula, em virtude de que a reflexão e a idealização do conteúdo de maneira adequada ficam prejudicados e, em decorrência disso, os alunos podem ser obrigados a abstrair de forma parcial ou limitada alguns fenômenos que se manifestam na natureza. Estas operações mentais de abstração, também conhecida como habilidades espaciais ou habilidades de visualização espacial, são definidas por Yilmaz et al. (2015) como o conjunto das habilidades utilizadas pelo estudante para visualizar objetos na mente, conhecê-los de diferentes perspectivas e transladá-los.

Quanto ao desenvolvimento cognitivo dos estudantes, Gruber et al. (2011) afirmam que, de um ponto de vista pedagógico, atividades experimentais proporcionadas pela realidade aumentada (RA) encorajam a construção de modelos mentais baseados nas observações práticas dos conceitos e princípios envolvidos, criando a conexão entre teoria e realidade, especialmente em tópicos que envolvem ciências tecnológicas. Além disso, quanto mais essas atividades incitarem a resolução de problemas práticos, mais qualificados serão os aprendizados desses alunos, uma vez que enriquecem e solidificam seus conhecimentos teóricos.

Diante de tais afirmações, este trabalho tem como objetivo detalhar a implementação de um aplicativo de RA capaz de contribuir no processo de ensino e aprendizagem de Física. Para tanto, busca promover o desenvolvimento da habilidade de visualização espacial por meio de experiências interativas com fenômenos da Física, que envolvem o uso de objetos 3D e simulações, assim como outras mídias educacionais que visam estimular a interação ativa de estudantes de maneira semelhante a experimentos práticos realizados em laboratórios reais.

\section{Desenvolvimento do Aplicativo}

O aplicativo de RA apresentado neste artigo consiste em um módulo para dispositivos móveis do Projeto AVATAR (Ambiente Virtual de Aprendizagem e Trabalho Acadêmico Remoto), projetado e desenvolvido pelos autores do artigo, tem como objetivo implementar formas de oportunizar a aprendizagem de Física ao estudante por meio de recursos multimídias que enfatizam a interação do usuário com os materiais pedagógicos. Para o desenvolvimento do aplicativo, realizaram-se as seguintes etapas: 
VII Congresso Brasileiro de Informática na Educação (CBIE 2018)

Anais dos Workshops do VII Congresso Brasileiro de Informática na Educação (WCBIE 2018)

$\mathrm{Na}$ primeira etapa foram analisadas e comparadas as ferramentas disponíveis para a implementação de aplicativos para dispositivos móveis com recursos de RA, sendo selecionadas as plataformas Unity 3D (2018) e Vuforia (2018), em virtude de ambas atenderem aos requisitos elencados para o desenvolvimento do Projeto. Os resultados desta análise comparativa podem ser encontrados em Herpich et al. (2017).

A segunda etapa do desenvolvimento consistiu no levantamento de requisitos e as respectivas estratégias de interação do usuário com o aplicativo de RA, em que este tem à disposição duas formas de interação com o aplicativo, citadas abaixo.

A primeira opção consiste no modo de interação "Integrado", no qual o usuário utiliza marcadores, cada um correspondente a um experimento, para visualizar e interagir com os recursos de RA em seu dispositivo móvel. Para tal, basta apenas apontar a câmera do dispositivo para um marcador e verificar os respectivos objetos educacionais que the são apresentados. Esta funcionalidade pode ser utilizada em sala de aula visto que oportuniza ao professor, que terá controle sobre quais marcadores estarão disponíveis para os alunos, maior facilidade na gerência dos conteúdos disponíveis ao longo do período letivo. Cada experimento conta com diferentes níveis de uma mesma simulação, permitindo que o aluno visualize e interaja com os recursos e as diferentes entidades abstratas relacionadas ao fenômeno físico em questão (Figura 1).

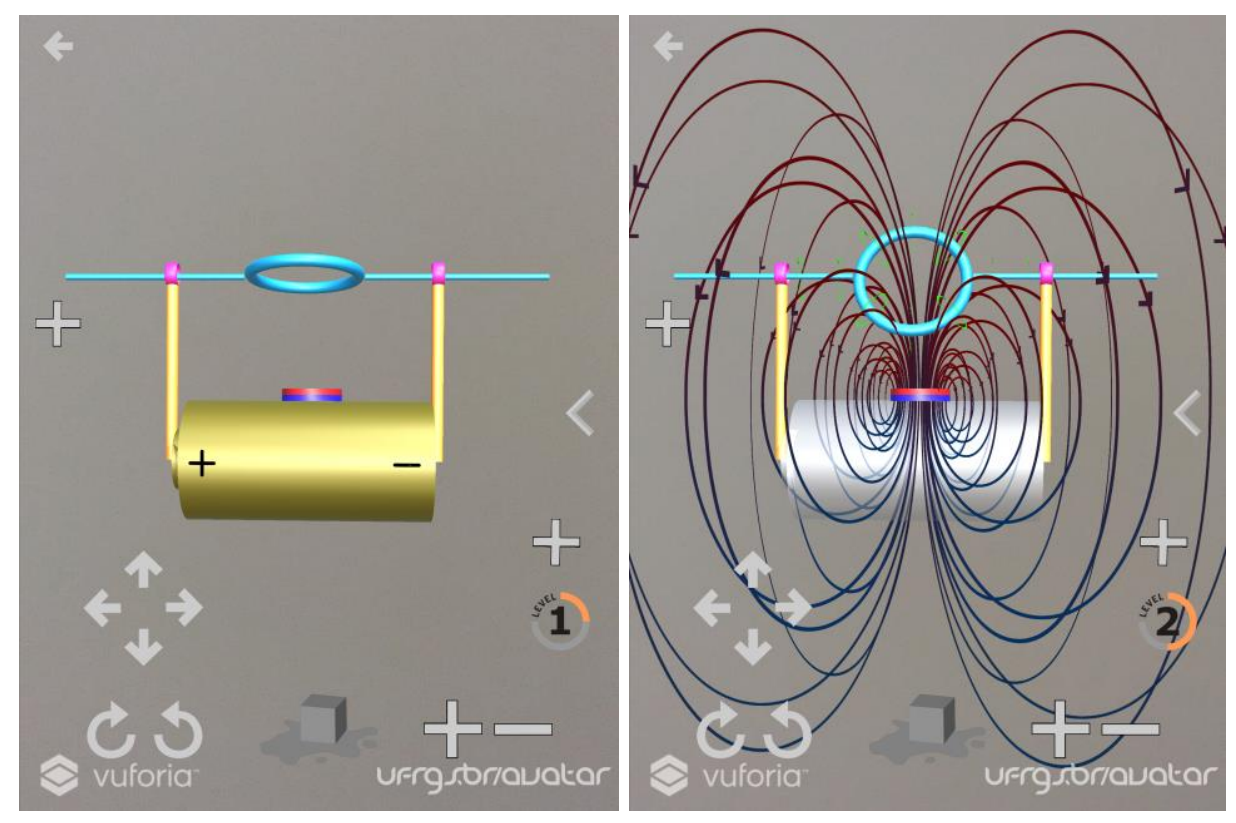

Figura 1. Motor elétrico e representação do campo magnético e elétrico

Já a segunda opção, denominada "Inventário", configura-se na interação do usuário com os recursos do aplicativo em um contexto cuja execução apresenta menores limitações por não ser necessário o uso de marcadores. Em vez disso, é permitido o acesso aos objetos educacionais em qualquer lugar e a qualquer momento. Essa forma de utilização é implementada através da visualização do conteúdo na tela do aplicativo sem interação com a câmera. Desse modo, são oferecidos ao usuário os mesmos elementos virtuais do modo "Integrado", porém exigindo menor performance por parte do dispositivo, o que expande a acessibilidade do aplicativo num aspecto econômico-social. 
VII Congresso Brasileiro de Informática na Educação (CBIE 2018)

Anais dos Workshops do VII Congresso Brasileiro de Informática na Educação (WCBIE 2018)

A terceira etapa está relacionada à elaboração do aplicativo, para a qual foi necessário a integração de diferentes frameworks. A ferramenta Unity 3D foi utilizada em conjunto com a linguagem de programação $\mathrm{C \#}$ para a implementação do aplicativo e exportação para as plataformas móveis. Para elaborar os recursos de realidade aumentada utilizou-se o SDK Vuforia. Ainda nessa etapa implementou-se o acesso às simulações em um modo offline, para ocasiões em que o usuário enfrente limitações na conexão com a internet.

\section{Conclusão}

O aplicativo apresentado neste artigo demonstra o potencial das tecnologias de realidade aumentada no processo pedagógico de estudantes de Física, uma vez que permite representar visualmente fenômenos que em geral são abstratos ou microscópicos. $\mathrm{O}$ principal benefício observado no aplicativo consiste na possibilidade da interação do estudante com recursos multimídia que, por sua vez, facilitam a assimilação dos conteúdos intrínsecos às mais diferentes áreas da Física.

Os recursos multimídia em realidade aumentada podem contribuir para o desenvolvimento das habilidades espaciais dos alunos e simplificar a visualização de princípios físicos, cujas representações muitas vezes não são suficientemente claras nos livros didáticos para auxiliar na abstração dos aprendizes. Outra vantagem do aplicativo consiste na portabilidade dos seus recursos educacionais, que podem ser acessados através de dispositivos móveis em qualquer hora e lugar, sem a necessidade de conexão com a internet.

\section{Referências}

Gruber, V., Schaeffer, L., Silva, J. B. \& Restivo, T. (2011). Model for remote data acquisition and monitoring integrating social media, NTIC's and $3 \mathrm{G}$ cell phone Networks applied to monitoring small wind turbine. Journal of Telecommunications, 7(1), 13-20.

Heck, C., Coelho, K. S., Simão, J. P. S., Silva, I. N., Silva, J. B. \& Bilessimo, S. M. S. (2016). Experiência de integração da experimentação remota no ensino de física do ensino médio: percepção dos alunos. Revista Novas Tecnologias Na Educação (RENOTE), 14(2), p. 1-10.

Herpich, F., Guarese, R. L. M. \& Tarouco, L. M. R. (2017). A Comparative Analysis of Augmented Reality Frameworks Aimed at the Development of Educational Applications. Creative Education, 8(9), p. 1433-1451.

PISA. (2018). Página oficial do PISA - Resultados da Avaliação de 2015. Disponível em $<$ http://portal.inep.gov.br/web/guest/acoes-internacionais/pisa/resultados $>$. Acesso: Julho de 2018.

Unity 3D. (2018). Página oficial. Disponível em $<$ http://unity3d.com $>$. Acesso: Julho de 2018.

Vuforia. (2018). Página oficial. Disponível em $<$ https://www.vuforia.com $>$. Acesso: Julho de 2018.

Yilmaz, R. M., Baydas, O., Karakus, T. \& Goktas, Y. (2015). An examination of interactions in a three-dimensional virtual world. Computers and Education, 88, p. 256-267. 